\title{
SimILARIDAdE ENTRE OS HABITATS DA VEGETAÇÃO DO Morro do Imperador, Juiz de Fora, Minas Gerais, COM BASE NA COMPOSIÇÃO DE SUA FLORA FANEROGÂMICA ${ }^{1}$
}

\author{
Daniel Salgado Pifano ${ }^{2,7}$, Arthur Sérgio Mouço Valente 2 , \\ Ricardo Montianele de Castro ${ }^{3}$, Marco Otávio Dias Pivari ${ }^{4}$, \\ Fátima Regina Gonçalves Salimena ${ }^{5}$ \& Ary Teixeira de Oliveira-Filho ${ }^{6}$
}

\begin{abstract}
RESUMO
(Similaridade entre os habitats da vegetação do Morro do Imperador, Juiz de Fora, Minas Gerais, com base na composição de sua flora fanerogâmica) Os objetivos deste estudo foram descrever a composição da flora fanerogâmica de um remanescente de vegetação do Domínio Atlântico situado no município de Juiz de Fora, Minas Gerais, utilizar análises de similaridade florística para relacionar suas variações com os três habitats de vegetação reconhecidos: Inselberg (afloramento rochoso), Interior e Borda da Floresta e comparar floristicamente os resultados encontrados com outras áreas de Mata Atlântica contempladas com levantamentos florísticos. Foram feitas coletas aleatórias de amostras de material botânico fértil em toda a área durante campanhas quinzenais que ocorreram entre abril de 2001 e janeiro de 2004, enriquecendo a coleção do herbário CESJ da Universidade Federal de Juiz de Fora. Foram registradas 373 espécies distribuídas em 255 gêneros e 87 famílias. A família Fabaceae foi a mais representativa em números de espécies (38), seguida de Asteraceae e Rubiaceae (24), além de Melastomataceae (20) e Solanaceae (17). O habitat com maior riqueza de espécies foi o Interior da Floresta, com 251; seguida pela Borda, com 211; e o Inselberg, com apenas dez. Os índices de similaridade mostraram que os três habitats têm composição florística muito distinta. Os resultados realçaram o grande valor do remanescente na manutenção da biodiversidade local.
\end{abstract} Palavras-chave: composição florística, Mata Atlântica, similaridade florística.

\section{Abstract}

(Plant similarity between different habitats of the Morro do Imperador, Juiz de Fora, Minas Gerais, based on the composition of its flowering plant flora) The objectives of this study were to describe the composition of the vascular flora of a native vegetation remnant of the Atlantic Domain, located in Juiz de Fora, SE Brazil, to use floristic similarity analyses to compare its variation with three recognized plant habitats: Inselberg (rock outcrop), Forest Edge and Forest Interior, and to compare the results found with similar research published for other areas of the Atlantic Forests. Plant specimens were randomly collected throughout the area in fortnightly fieldwork carried out between April 2001 and January 2004, enriching the colection of the Herbarium of the Federal University of Juiz de Fora (CESJ). The total of species found was 375, distributed in 257 genera and 89 families. Fabaceae was the most representative family with the highest number of species (38), followed by Asteraceae and Rubiaceae (24), Melastomataceae (20) and Solanaceae (17). The richest habitat was the Forest Interior, with 251 species; followed by the Edge, with 211; and the Inselberg, with only ten. The similarity indices showed that all three habitats have very distinct in floristic composition. The results highlight the great value of forest fragments in the maintenance of local biodiversity. Key-words: floristic composition, Atlantic Forest domain, floristic similarity.

\section{INTRODUÇÃo}

O Domínio da Mata Atlântica estende-se de $6^{\circ}$ a $30^{\circ} \mathrm{S}$ ao longo da costa brasileira e corresponde a $16 \%$ do território nacional (SOS Mata Atlântica \& INPE 2002). As discussões sobre a amplitude e os limites do Domínio, no sentido do interior do país, são muitas, provocando divergências na aplicação de terminologias adequadas e, mesmo, no reconhecimento das fitofisionomias em regiões transicionais ou de

Artigo recebido em 12/2006. Aceito para publicação em 07/2007.

${ }^{1}$ Parte da Dissertação do primeiro autor, desenvolvida no programa Programa de Pós-graduação em Engenharia Florestal da Universidade Federal de Lavras.

${ }^{2}$ Biólogo, discente do programa de Pós-graduação em Ciências Florestais da Universidade Federal de Lavras.

${ }^{3}$ Biólogo, M.Sc. pelo programa de Pós graduação em Botânica da Universidade Estadual de Feira de Santana.

${ }^{4}$ Biólogo, discente do programa de Pós-graduação em Biologia Vegetal da Universidade Federal de Minas Gerais.

${ }^{5}$ Professora Adjunta do Departamento de Botânica, Universidade Federal de Juiz de Fora.

${ }^{6}$ Professor Titular do Departamento de Ciências Florestais da Universidade Federal de Lavras.

${ }^{7}$ Endereço para correspondência: Rua Nair Verônica de Jesus no 105/201, Bairro Olaria, Lavras, MG, 37200-000, Brasil.

danielfloristico@yahoo.com.br 
ecotóno (Fernandes 2003). No âmbito das prerrogativas legais, o Decreto Federal $n^{\circ} 750$ de 10 de fevereiro de 1993, entre outros avanços, definiu e regulamentou a área de abrangência da Mata Atlântica incluindo as formações interioranas, tornando-se posteriormente uma importante ferramenta para a consolidação de um novo entendimento a respeito do que é realmente o Domínio Atlântico e quais fisionomias, florestais ou não, que nele estão incluídas (SOS Mata Atlântica 1998).

De acordo com esta nova abordagem, o Domínio Atlântico no estado de Minas Gerais contém todas as principais fisionomias florestais brasileiras, conforme definidas pelo IBGE (Veloso et al. 1991): Florestas Ombrófila Densa, Ombrófila Mista, Ombrófila Aberta, Estacional Semidecidual e Estacional Decidual. No entanto, é a Floresta Estacional Semidecidual que predomina, constituindo mais de $85 \%$ da área florestal original do Domínio Atlântico em Minas Gerais (Scolforo \& Carvalho 2006). Sua distribuição primitiva concentrava-se no leste e sul do estado e revestia a quase totalidade da Zona da Mata (Veloso \& Goes-Filho 1982). O continuum florestal descrito por Aubréville (1959), que ia desde o Espírito Santo até Belo Horizonte, acompanhando as extensões da serra da Mantiqueira, foi gradativamente substituído por monoculturas e formação de pastos a partir de meados do séc XIX (Paniago 1983).

A ocupação desordenada do solo mineiro, para a exploração do cultivo de café, alcançou inclusive a Zona da Mata, provocando a devastação de imensas áreas florestais. Neste contexto, a vegetação original dessas regiões ficou hoje reduzida a remanescentes florestais esparsos, sendo que a maioria acha-se bastante perturbada pela intervenção humana (MeiraNeto et al. 1997).

A sub-região da Zona da Mata Sul, cujo maior núcleo urbano é a cidade de Juiz de Fora, corresponde à vertente norte do terço final da bacia do Rio Paraíba do Sul (IBGE 1981) e é ainda relativamente desconhecida floristicamente. Durante mais de quatro décadas a última publicação contendo uma relação de espécies típicas da Zona da Mata de Minas Gerais foi uma obra publicada no INPA por Ezechias P. Heringer (Heringer 1947). Foi somente a partir da década de 1990 que levantamentos florísticos começaram a ser produzidos por pesquisadores da Universidade Federal de Viçosa (Meira-Neto \& Martins 2000; Meira-Neto \& Martins 2002; Ribas et al. 2003; Silva et al. 2004). No entanto, a microrregião de Viçosa está situada na Zona da Mata Norte, próxima ao divisor de águas que limita as bacias do rio Paraíba do Sul e rio Doce (Castro 1980). Entre os levantamentos florísticos realizados na Zona da Mata Sul, destacam-se apenas os realizados na Matinha do Centro Olímpico, no campus da Universidade Federal de Juiz de Fora, UFJF (Almeida \& Souza 1997) e na Serra dos Núcleos, Município de São João Nepomuceno (Castro et al. 2004). Outros levantamentos encontram-se ainda na forma de dissertações, monografias e projetos com publicação pendente, como aqueles realizados na Reserva Biológica da Represa do Grama, Município de Descoberto (Pifano 2007) e no Parque Estadual do Ibitipoca e seu entorno, Município de Lima Duarte (Almeida 1996; Fontes 1997; A.S.M. Valente, dados não publicados).

Os principais objetivos do presente trabalho foram: (a) levantar a flora fanerogâmica do Morro do Imperador; (b) descrever a distribuição das espécies nos três habitats do remanescente; (c) comparar a flora destes habitats por meio de análise de similaridade e (d) comparar floristicamente os resultados encontrados com outras áreas de Mata Atlântica contempladas com levantamentos florísticos. Espera-se assim contribuir para enriquecer o conhecimento sobre a flora do Município de Juiz de Fora e da Zona da Mata Sul, na expectativa de agregar valor de conservação a estes remanescentes.

\section{Material e Métodos \\ Área de estudos}

O município de Juiz de Fora possui uma área total de $1.424 \mathrm{~km}^{2}$ e está situado no sudeste do estado de Minas Gerais entre as coordenadas $21^{\circ} 34^{\prime}$ e $22^{\circ} 05^{\prime}$ de latitude sul e $43^{\circ} 09^{\prime}$ e $43^{\circ} 45^{\prime}$ de longitude oeste. O relevo é acidentado e caracterizado por morros mamelonares e inselbergs 
(batólitos graníticos e/ou gnáissicos aflorados); a altitude varia de 467 a $1.104 \mathrm{~m}$. Segundo a classificação de Köppen, possui clima Cwa e Cwb (tropical de altitude com verões quentes). A temperatura média anual fica em torno de $22,5^{\circ} \mathrm{C}$ e média pluviométrica de $1.470 \mathrm{~mm} \mathrm{ano}^{-1}$ (Borges 2006).

Conhecido também como Morro do Cristo e Morro da Liberdade, o Morro do Imperador está situado nas coordenadas $21^{\circ} 45^{\prime} 13^{\prime \prime /}$ $21^{\circ} 46^{\prime} 13^{\prime \prime S}$ e $43^{\circ} 21^{\prime} 19^{\prime \prime} / 43^{\circ} 22^{\prime} 15^{\prime \prime} \mathrm{W}$, alcança $923 \mathrm{~m}$ de altitude constituindo um dos pontos mais altos do município. O Morro do Imperador é assim denominado porque, em 1861, d. Pedro II o escalou para apreciar a vista da cidade.

Localizado na região central do município, representa um marco referencial da cidade e um importante ponto turístico conhecido como mirante do Cristo. De acordo com Fonseca \& Viera (1995), a área foi tombada pelos Decretos Municipais 4312/90 e 4355/90 e apresenta cerca de 78 ha, pertencente a proprietários diversos, sendo que $84,2 \%$ está ocupada pela escarpa íngreme do inselberg e por dois fragmentos de mata separados entre si: um a oeste (cerca de 53 ha) e outro a leste (cerca de 25 ha) do marco zero do Município, sendo o do oeste maior e cortado por uma importante via de acesso do centro à zona oeste da cidade. $\mathrm{O}$ restante da área é composto por vegetação rasteira e pastagens (Fig. 1). A mata em questão é classificada como Floresta Estacional Semidecidual Submontana, no sistema do IBGE (Veloso et al. 1991), e integra o domínio da Mata Atlântica (Oliveira-Filho \& Fontes 2000), em conformidade com Decreto Federal 750/93.

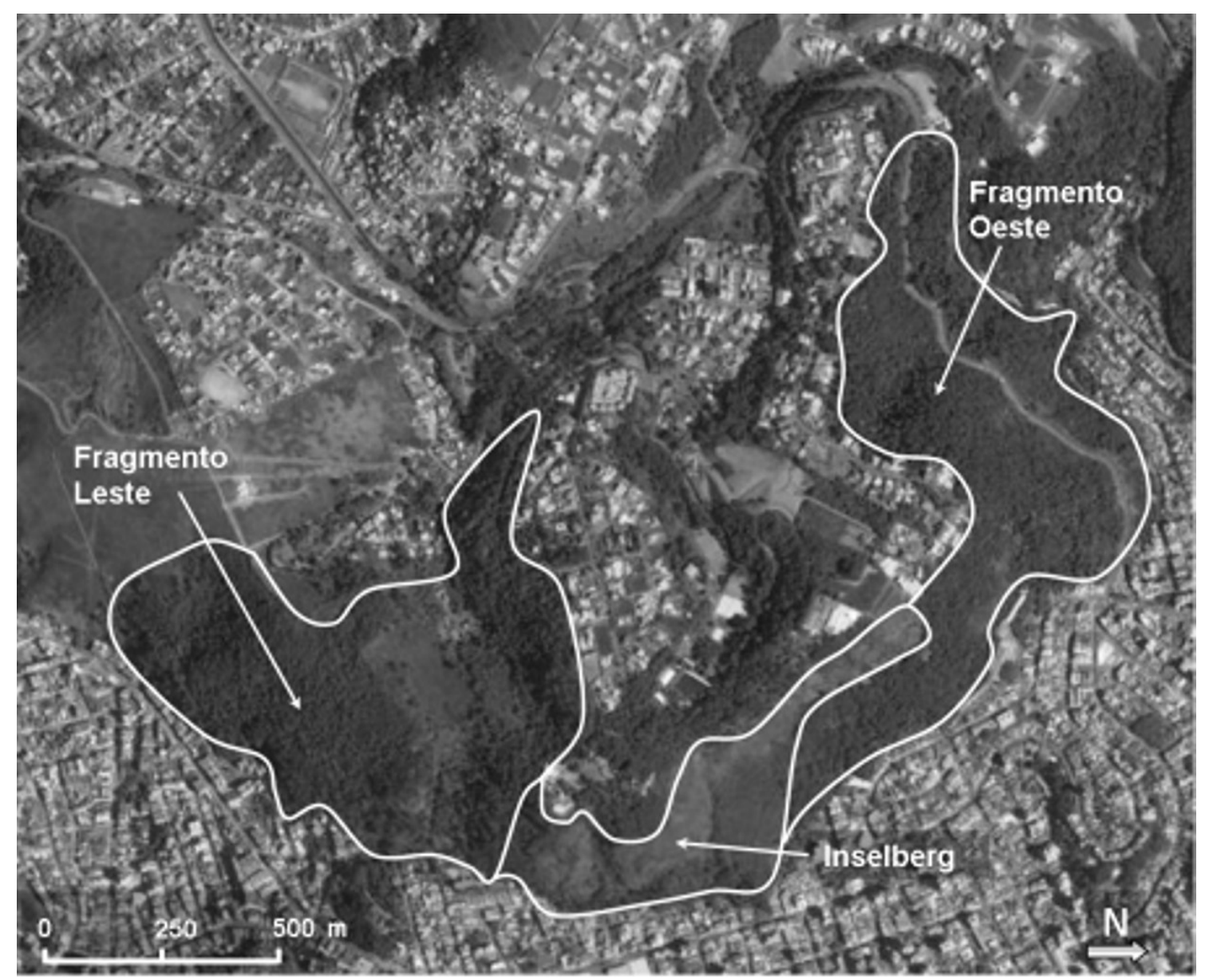

Figura 1 - Imagem da mata Morro do Imperador, Juiz de Fora, Minas Gerais com o posicionamento do Inselberg separando os fragmentos leste e oeste. Fonte: Google Earth () 2007 Europa Tecnologie - Image (c) 2006 DigitalGlobe. 


\section{Levantamento Florístico}

O levantamento florístico do Morro do Imperador foi feito por meio de uma série de campanhas de campo para coleta de material botânico realizadas a intervalos quinzenais, durante os anos de 2001 a 2004. As campanhas de campo consistiram em caminhadas aleatórias percorrendo toda a área tombada do Morro do Imperador.

Coletaram-se indistintamente amostras de material botânico das espécies de fanerógamas em seus respectivos hábitos ocorrentes na floresta, notificando para cada espécime o local onde foi encontrado, além de dados que poderiam ser perdidos nos processos de herborização como cheiro, cor presença de látex ou resina etc. Apenas materiais em estágio reprodutivo foram coletados. Para o hábito arbóreo utilizaram-se materiais e técnicas de arborismo, além da tesoura de poda acoplada conhecida como podão. Tais técnicas também foram adaptadas para as plantas saxícolas devido à inerente dificuldade de se coletar em inselbergs. É importante mencionar que, na separação dos hábitos, as arvoretas foram incluídas no hábito arbóreo, sendo as plantas eretas e lenhosas distintas apenas como arbustos ou árvores. Para tal, seguiu-se a classificação das formas de vida de Raunkiaer (1934) adaptada aos conceitos de organografia atuais. Os espécimes coletados foram herborizados e encontram-se depositados como testemunho no herbário CESJ da Universidade Federal de Juiz de Fora.

Para a identificação e determinação dos táxons, foram utilizadas chaves dicotômicas, monografias, teses, dissertações e bibliografias específicas de cada táxon, além de consultas a especialistas e a herbários nacionais. Todos os táxons foram classificados em famílias segundo o sistema do APGII (2003) e com auxílio da obra de Souza \& Lorenzi (2005).

\section{Análises florísticas}

A vegetação da área foi classificada em três fisionomias distintas para definição dos habitats: Borda e Interior da Floresta e Inselberg.
A delimitação dos habitats foi feita com auxílio de um GPS, mapas e imagens disponibilizadas pela prefeitura. A separação entre Borda e Interior da Floresta mereceu atenção especial devido às dificuldades oferecidas pelo relevo muito íngreme e pela própria conformação espacial da área, que é extremamente irregular em ambas as faces. Outro fator importante já relatado é a presença da via de acesso que corta a face oeste do remanescente, que exigiu maior acurácia na definição dos limites e, conseqüentemente, na definição do que era exatamente a Borda. Sendo assim, a constatação de grupos indicadores de Borda de floresta como os gêneros; Miconia, Vismia e Davilla (Armelin \& Mantovani 2001; OliveiraFilho \& Fluminhan-Filho 1999; Oliveira-Filho et al. 2004; Nascimento e Laurence 2006) além da estrutura vertical (observada) foram fundamentais como auxílio na definição e formulação de limites. Para análise da similaridade florística entre os habitats foram utilizados diagramas de Venn além dos índices de similaridade de Sorensen e Jaccard (Kent \& Coker 1992). Utilizaram-se os dois índices a fim de verificar se a diferença existente na formulação dos mesmos interfere significativamente na interpretação dos resultados.

\section{Resultados}

O levantamento da flora do Morro do Imperador registrou 373 espécies de fanerógamas distribuídas em 255 gêneros e 87 famílias de Angiospermas (Tab. 1); não foi registrada nenhuma Gymnosperma, embora um indivíduo de Araucaria angustifolia ocorresse sempre estéril no fragmento leste durante as campanhas de campo. A família mais representativa foi Fabaceae, com 38 espécies (10,1\% da riqueza total de espécies); seguida de Asteraceae e Rubiaceae, com 24 (6,4\%); Melastomataceae, com $20(5,3 \%)$ e Solanaceae, com 17 espécies $(4,5 \%)$. Essas famílias acumularam $32,7 \%$ da riqueza florística total.

Os gêneros mais representativos foram Psychotria, com dez espécies, e Solanum, com 
nove, seguidos de Piper e Miconia, com seis cada. Muitos gêneros; como Polygala, Leandra, Mimosa, Machaerium, Ocotea e Croton, apresentaram quatro espécies. Porém, a maioria deles (195) mostrou-se com apenas uma única espécie. Duas espécies de trepadeira foram relatadas pelos respectivos especialistas como primeiras ocorrências, Cissampelos verticillata ocorreu como um primeiro registro da espécie para o Brasil (J.M.Braga, com. pess.) e Heteropterys pauciflora foi relatada como um primeiro registro para o estado de Minas Gerais, uma vez que sua distribuição restringia-se aos limites geográficos impostos pela Serra do Mar (A.Amorim, com. pess.).

O hábito com maior representatividade foi o arbóreo, com 153 espécies. Os arbustos com 84, as trepadeiras, com 70, e as ervas, com 61 espécies, constituem o grupo dos hábitos com um número intermediário. Já as epífitas correspondem ao hábito menos representativo, com apenas seis espécies. A distribuição dos mesmos na floresta segue um mosaico variado em função do habitat. Trepadeiras herbáceas e espinhentas, arbustos e pequenas árvores predominam na Borda da Floresta e seis das oito espécies de epífitas são restritas ao Interior da Floresta, onde é possível observar um dossel mais fechado com árvores emergentes (mais de $30 \mathrm{~m}$ ) das espécies Vochysia magnifica e Lecythis pisonis. Ainda no Interior, as trepadeiras herbáceas dão lugar às grandes lianas que alcançam o dossel, o subosque é denso e o estrato inferior dominado por bromélias terrestres, como Ananas bracteatus e Bromelia antiacantha. Das dez espécies encontradas no Inselberg, oito são exclusivas e apenas duas foram encontradas também na Borda da Floresta: Leandra aurea. e Talinum patens. Espécies como Nanuza plicata e Sinningia agreggata são comumente citadas para o habitat de Inselberg (afloramento rochoso granito-gnaíssico), sendo ambas indicadoras do mesmo nas Florestas Estacionais Semideciduais (A. Chautems., com pess.).

O hábitat com maior riqueza florística foi o Interior, com 251 espécies $(67,3 \%$ do total). Já a Borda apresenta 211 (56,5\%) e o Inselberg apenas $10(2,7 \%)$. É importante ressaltar que os dados acima não incluem somente as espécies exclusivas de cada hábitat, considerando aquelas que podem ocorrer em mais de um. Na Borda, 62,1\% das espécies encontradas são árvores e arbustos, 21,3\% são trepadeiras, $15,6 \%$ ervas e $1 \%$ são epífitas; no Interior, $70,5 \%$ são árvores e arbustos, $15,1 \%$ são trepadeiras, $11,1 \%$ são ervas e 3,2\% são epífitas. No Inselberg não ocorreram árvores e epífitas, sendo $70 \%$ de ervas, $20 \%$ de trepadeiras e $10 \%$ de arbustos.

As similaridades florísticas entre os três habitats calculadas pelos índices de Sorensen e Jaccard (Tab. 2) bem como o diagrama de Venn (Fig. 2) mostram que, entre os três habitats, o Inselberg tem flora muito distinta, uma vez que o número de espécies compartilhadas com os habitats florestais é muito pequeno, nenhuma para o Interior e apenas duas com a Borda. Apenas entre a Borda e o Interior da Floresta é que o número de espécies compartilhadas torna-se expressivo: $37,8 \%$ das espécies de Borda e $45 \%$ das de Interior são também encontradas em ambos os habitats. Ainda assim, os dois habitats são bem distintos, uma vez que mais de metade de suas espécies são exclusivas dos mesmos.

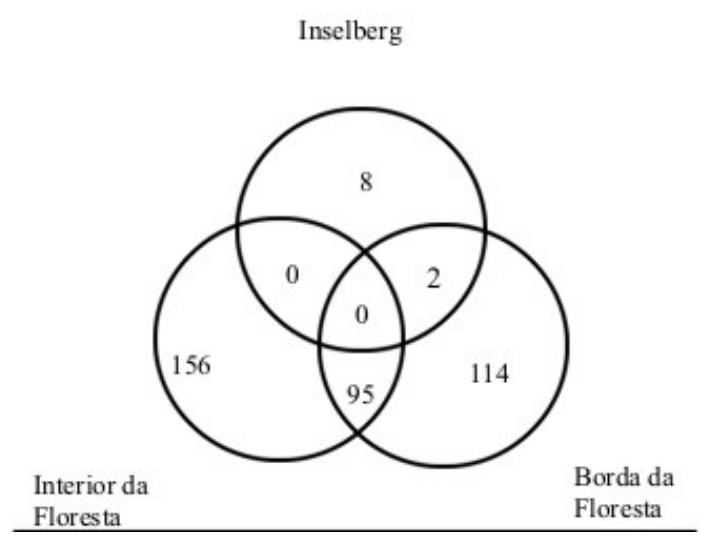

Figura 2 - Diagrama de Venn mostrando o número de espécies exclusivas e comuns entre três habitats do Morro do Imperador, Juiz de Fora, MG. 
Tabela 1 - Relação das espécies registradas na flora fanerogâmica do Morro do Imperador seguidas de seus respectivos hábitos, ocorrência nos três habitats pré-definidos e números de registro no herbário CESJ.

\begin{tabular}{|c|c|c|c|c|c|}
\hline Famílias e espécies & Hábito & Borda & Interior & Inselberg & CESJ \\
\hline \multicolumn{6}{|l|}{ ACANTHACEAE } \\
\hline Dicliptera mucronifolia Nees & arbusto & & $X$ & & 8497 \\
\hline Mendoncia mollis Lindau & trepadeira & $X$ & $\mathrm{X}$ & & 40083 \\
\hline Ruellia aff. sanguinea Griseb. & arbusto & & $\mathrm{X}$ & & 36676 \\
\hline Ruellia elegans Poir. & arbusto & $\mathrm{X}$ & $\mathrm{X}$ & & 39141 \\
\hline Ruellia macrantha Lindau & arbusto & $\mathrm{X}$ & & & 33100 \\
\hline Thunbergia alata Bojer ex Sims & arbusto & $\mathrm{X}$ & $X$ & & 34021 \\
\hline \multicolumn{6}{|l|}{ ACHARIACEAE } \\
\hline Carpotroche brasiliensis (Raddi) Endl. & árvore & & $\mathrm{X}$ & & 27778 \\
\hline \multicolumn{6}{|l|}{ AMARANTHACEAE } \\
\hline Alternanthera brasiliana (L.) Kuntze & erva & $\mathrm{X}$ & $\mathrm{X}$ & & 34995 \\
\hline \multicolumn{6}{|l|}{ ANACARDIACEAE } \\
\hline Schinus terebinthifolius Raddi & árvore & $\mathrm{X}$ & $\mathrm{X}$ & & 32516 \\
\hline Tapirira obtusa (Benth.) D.J.Mitch. & árvore & $\mathrm{X}$ & & & 33966 \\
\hline \multicolumn{6}{|l|}{ ANNONACEAE } \\
\hline Annona cacans Warm. & árvore & & $\mathrm{X}$ & & 35697 \\
\hline Duguetia lanceolata A.St.-Hil. & árvore & & $\mathrm{X}$ & & 32569 \\
\hline Guatteria australis A.St.-Hil. & árvore & & $\mathrm{X}$ & & 27738 \\
\hline Rollinia dolabripetala (Raddi) R.E.Fr. & árvore & $\mathrm{X}$ & $\mathrm{X}$ & & 27737 \\
\hline Rollinia laurifolia Schltdl. & árvore & $\mathrm{X}$ & $\mathrm{X}$ & & 36521 \\
\hline Xilopia brasiliensis Spreng. & árvore & $\mathrm{X}$ & $\mathrm{X}$ & & 31210 \\
\hline Xilopia sericea A.St.-Hil. & árvore & $\mathrm{X}$ & $\mathrm{X}$ & & 27736 \\
\hline \multicolumn{6}{|l|}{ APOCYNACEAE } \\
\hline Asclepias curassavica $\mathrm{L}$. & erva & $\mathrm{X}$ & $\mathrm{X}$ & & 37181 \\
\hline Mandevilla splendens (Hook.) Woodson & trepadeira & & & $X$ & 35156 \\
\hline Oxypetalum riparium Kunth. & trepadeira & $\mathrm{X}$ & & & 32360 \\
\hline Oxypetalum subriparium Malme & trepadeira & $\mathrm{X}$ & & & 31416 \\
\hline Tabernaemontana laeta Mart. & árvore & & $\mathrm{X}$ & & 39143 \\
\hline \multicolumn{6}{|l|}{ AQUIFOLIACEAE } \\
\hline Ilex cerasifolia Reissek & árvore & & $\mathrm{X}$ & & 27962 \\
\hline Ilex theazens Mart. ex Reissek & árvore & & $\mathrm{X}$ & & 27778 \\
\hline \multicolumn{6}{|l|}{ ARACEAE } \\
\hline Anthurium solitarium $\mathrm{Schott}$ & erva & & & $\mathrm{X}$ & 35153 \\
\hline \multicolumn{6}{|l|}{ ARALIACEAE } \\
\hline Dendropanax cuneatus (DC.) Decne. \& Planch. & árvore & & $\mathrm{X}$ & & 32599 \\
\hline $\begin{array}{l}\text { Schefflera morototoni (Aubl.) Maguire, } \\
\text { Steyermark \& Frodin }\end{array}$ & árvore & & $\mathrm{X}$ & & 27741 \\
\hline \multicolumn{6}{|l|}{ ARECACEAE } \\
\hline Astrocarium aculeatissimum (Schott) Burret & árvore & $\mathrm{X}$ & $\mathrm{X}$ & & 36522 \\
\hline Geonoma brevispata Barb. Rodr. & árvore & & $\mathrm{X}$ & & 32511 \\
\hline Syagrus romanzoffiana (Cham.) Glassman & árvore & $\mathrm{X}$ & $\mathrm{X}$ & & 35860 \\
\hline \multicolumn{6}{|l|}{ ARISTOLOCHIACEAE } \\
\hline Aristolochia melastoma Silva Manso ex Duch. & trepadeira & & $\mathrm{X}$ & & 36679 \\
\hline
\end{tabular}




\begin{tabular}{|c|c|c|c|c|c|}
\hline Famílias e espécies & Hábito & Borda & Interior & Inselberg & CESJ \\
\hline \multicolumn{6}{|l|}{ ASTERACEAE } \\
\hline $\begin{array}{l}\text { Austrocritonia velutina (Gard.) } \\
\text { R.M.King \& H.Rob. }\end{array}$ & arbusto & $\mathrm{X}$ & & & 37183 \\
\hline $\begin{array}{l}\text { Austroeupatorium inulaefolium (Kunth.) } \\
\text { R.M.King \& H.Rob. }\end{array}$ & arbusto & $\mathrm{X}$ & & & 34022 \\
\hline Baccharis dracunculifolia DC. & arbusto & $\mathrm{X}$ & & & 33889 \\
\hline Baccharis sagitalis DC. & arbusto & $\mathrm{X}$ & & & 40075 \\
\hline Baccharis serrulata Pers. & arbusto & $X$ & & & 39139 \\
\hline Bidens segetum Mart. ex Colla & trepadeira & & $\mathrm{X}$ & & 8452 \\
\hline Brainvillea biaristata DC. & arbusto & $\mathrm{X}$ & $\mathrm{X}$ & & 8470 \\
\hline Colea pinnatifida Less. & arbusto & & $\mathrm{X}$ & & 38418 \\
\hline Dasyphyllum brasiliense (Spreng.) Cabrera & árvore & & $\mathrm{X}$ & & 34128 \\
\hline Eupatorium vauthierianum DC. & arbusto & $\mathrm{X}$ & $\mathrm{X}$ & & 38414 \\
\hline Eupatorium maximillianii Schrad & arbusto & $\mathrm{X}$ & & & 37685 \\
\hline Eupatorium sp. & arbusto & & $\mathrm{X}$ & & 38520 \\
\hline Heterocondylus alatus (Vell.) R.M.King \& H.Rob. & arbusto & $\mathrm{X}$ & $\mathrm{X}$ & & 34506 \\
\hline Mikania buddleiaefolia DC. & trepadeira & & $\mathrm{X}$ & & 37182 \\
\hline Mikania cf. trichophylla DC. & trepadeira & $\mathrm{X}$ & & & 36163 \\
\hline Piptocarpha macropoda (DC.) Baker & árvore & & $\mathrm{X}$ & & 35035 \\
\hline Trixis anthimenorrhoea Mart. & arbusto & $\mathrm{X}$ & $\mathrm{X}$ & & 35048 \\
\hline Verbesina glabrata Hook. \& Arn. & arbusto & & $\mathrm{X}$ & & 35058 \\
\hline Vernonia aurea Mart. ex DC. & arbusto & & $\mathrm{X}$ & & 35132 \\
\hline Vernonia muricata DC. & arbusto & $\mathrm{X}$ & $\mathrm{X}$ & & 35059 \\
\hline Vernonia petiolaris DC. & arbusto & $\mathrm{X}$ & & & 36500 \\
\hline Vernonia sp. & arbusto & $\mathrm{X}$ & & & 28563 \\
\hline Vernonanthura divaricata (Spreng.) H.Rob. & árvore & $\mathrm{X}$ & $\mathrm{X}$ & & 34183 \\
\hline Wulffia stenoglossa (Cass.) DC. & trepadeira & & $\mathrm{X}$ & & 32510 \\
\hline \multicolumn{6}{|l|}{ BALSAMINACEAE } \\
\hline Impatiens decumbens $\mathrm{L}$. & erva & & $\mathrm{X}$ & & 32696 \\
\hline \multicolumn{6}{|l|}{ BEGONIACEAE } \\
\hline Begonia digitata Raddi & erva & & $\mathrm{X}$ & & 27752 \\
\hline \multicolumn{6}{|l|}{ BIGNONIACEAE } \\
\hline Anemopaegma setilobum A.H.Gentry & trepadeira & $\mathrm{X}$ & & & 40077 \\
\hline Arrabidaea ateramnantha Bur. ex K.Schum. & trepadeira & $\mathrm{X}$ & $\mathrm{X}$ & & 40091 \\
\hline Arrabidaea leucopogon (Cham.) Sandwith & trepadeira & $\mathrm{X}$ & & & 32064 \\
\hline $\begin{array}{l}\text { Arrabidaea triplinervia (Mart. ex DC.) } \\
\text { Baill. ex Bureau. }\end{array}$ & trepadeira & $\mathrm{X}$ & $\mathrm{X}$ & & 34606 \\
\hline Cybistax antisyphilitica (Mart.) Mart. & árvore & $\mathrm{X}$ & & & 29644 \\
\hline Fridericia speciosa Mart. & trepadeira & $\mathrm{X}$ & & & 37689 \\
\hline Jacaranda micrantha Cham. & árvore & $\mathrm{X}$ & $\mathrm{X}$ & & 32497 \\
\hline Pyrostegia venusta (Ker Gawl.) Miers & trepadeira & $\mathrm{X}$ & & & 27743 \\
\hline Sparattosperma leucanthum (Vell.) K.Schum. & árvore & $\mathrm{X}$ & $\mathrm{X}$ & & $27743 \mathrm{a}$ \\
\hline Tabebuia chrysothrica (Mart. ex DC.) Standl. & árvore & $\mathrm{X}$ & & & 34181 \\
\hline Tabebuia impetiginosa (Mart. ex DC.) Standl. & árvore & & $\mathrm{X}$ & & 39656 \\
\hline \multicolumn{6}{|l|}{ BORAGINACEAE } \\
\hline Cordia sellowiana Cham. & árvore & $\mathrm{X}$ & $\mathrm{X}$ & & 37918 \\
\hline Cordia trichoclada DC. & árvore & $\mathrm{X}$ & $\mathrm{X}$ & & 36154 \\
\hline Tournefortia paniculata Vent. & trepadeira & $\mathrm{X}$ & & & 36158 \\
\hline
\end{tabular}




\begin{tabular}{|c|c|c|c|c|c|}
\hline Famílias e espécies & Hábito & Borda & Interior & Inselberg & CESJ \\
\hline \multicolumn{6}{|l|}{ BROMELIACEAE } \\
\hline Ananas bracteatus (Lindl.) Schult. \& Schult.f. & erva & $\mathrm{X}$ & $X$ & & 32505 \\
\hline Bromelia antiacantha Bertol. & erva & $\mathrm{X}$ & $\mathrm{X}$ & & 15921 \\
\hline Portea petropolitana (Wawra) Mez. & epífita & $\mathrm{X}$ & $\mathrm{X}$ & & 39138 \\
\hline Pitcairnia flammea Lindl. & erva & & & $\mathrm{X}$ & 37200 \\
\hline Tillandsia gardnerii Lindl. & epífita & $\mathrm{X}$ & $\mathrm{X}$ & & 37561 \\
\hline \multicolumn{6}{|l|}{ BURSERACEAE } \\
\hline Protium brasiliense (Spreng.) Engl. & árvore & & $\mathrm{X}$ & & 32629 \\
\hline \multicolumn{6}{|l|}{ CANNACEAE } \\
\hline Canna indica $\mathrm{L}$. & erva & & $\mathrm{X}$ & & 37189 \\
\hline \multicolumn{6}{|l|}{ CACTACEAE } \\
\hline Hatiora salicornioides (Haw.) Britton \& Rose & epífita & & $\mathrm{X}$ & & 32495 \\
\hline Rhipsalis lindbergiana K.Schum. & epífita & & $\mathrm{X}$ & & 37552 \\
\hline \multicolumn{6}{|l|}{ CAMPANULACEAE } \\
\hline Lobelia exaltata Pohl & arbusto & $\mathrm{X}$ & & & 34020 \\
\hline \multicolumn{6}{|l|}{ CANNABACEAE } \\
\hline Celtis brasiliensis (Gard.) Planch. & árvore & $\mathrm{X}$ & $\mathrm{X}$ & & 32500 \\
\hline Celtis iguanaea (Jacq.) Sarg. & árvore & & $\mathrm{X}$ & & 40981 \\
\hline Trema micrantha (L.) Blume & árvore & $\mathrm{X}$ & & & 34747 \\
\hline \multicolumn{6}{|l|}{ CELASTRACEAE } \\
\hline Cheiloclinium cognatum (Miers.) A.C.Sm. & árvore & & $\mathrm{X}$ & & 33901 \\
\hline Maytenus evonymoides Reissek & árvore & & $\mathrm{X}$ & & 39850 \\
\hline Maytenus salicifolia Reissek & árvore & & $X$ & & 38331 \\
\hline \multicolumn{6}{|l|}{ CHRYSOBALANACEAE } \\
\hline Hirtella hebeclada Moric. & árvore & & $\mathrm{X}$ & & 31166 \\
\hline \multicolumn{6}{|l|}{ CLUSIACEAE } \\
\hline Garcinia brasiliensis Mart. & árvore & & $\mathrm{X}$ & & 36524 \\
\hline \multicolumn{6}{|l|}{ COMMELINACEAE } \\
\hline Commelina sp. & erva & & $\mathrm{X}$ & & 35036 \\
\hline Tripogandra sp. & erva & $\mathrm{X}$ & & & 36157 \\
\hline \multicolumn{6}{|l|}{ CONVOLVULACEAE } \\
\hline Ipomoea purpurea (L.) Roth. & trepadeira & $\mathrm{X}$ & $\mathrm{X}$ & & 37690 \\
\hline Jacquemontia multiflora Haller f & trepadeira & & $\mathrm{X}$ & & 33906 \\
\hline Merremia macrocalyx (Ruiz ex Pav.) O’Donell & trepadeira & $\mathrm{X}$ & & & 37180 \\
\hline \multicolumn{6}{|l|}{ COSTACEAE } \\
\hline Costus spiralis (Jacq.) Roscoe & erva & & $\mathrm{X}$ & & 28763 \\
\hline \multicolumn{6}{|l|}{ CUCURBITACEAE } \\
\hline Cayaponia sp. & trepadeira & $\mathrm{X}$ & $\mathrm{X}$ & & 40568 \\
\hline Melothria fluminensis Gard. & trepadeira & $\mathrm{X}$ & & & 32979 \\
\hline Melothrianthus smilacifolius (Cogn.) M.Crovetto & trepadeira & & $\mathrm{X}$ & & 38416 \\
\hline Wilbrandia hibiscoides Silva Manso & trepadeira & & $\mathrm{X}$ & & 36210 \\
\hline \multicolumn{6}{|l|}{ CUNONIACEAE } \\
\hline Lamanonia grandistipularis (Taub.) Taub. & árvore & $\mathrm{X}$ & $\mathrm{X}$ & & 40854 \\
\hline Lamanonia ternata Vell. & árvore & $\mathrm{X}$ & $\mathrm{X}$ & & 37555 \\
\hline \multicolumn{6}{|l|}{ CYPERACEAE } \\
\hline Cyperus aggregatus (Willd.) Endl. & erva & $\mathrm{X}$ & & & 35152 \\
\hline Cyperus coriifolius Boeck. & erva & & $\mathrm{X}$ & & 35331 \\
\hline
\end{tabular}




\begin{tabular}{|c|c|c|c|c|c|}
\hline Famílias e espécies & Hábito & Borda & Interior & Inselberg & CESJ \\
\hline Rynchospora exaltata Kunth. & erva & & $\mathrm{X}$ & & 33696 \\
\hline Scleria sp. & erva & & $\mathrm{X}$ & & 35329 \\
\hline \multicolumn{6}{|l|}{ DILLENIACEAE } \\
\hline Davilla elliptica A.St.-Hil. & trepadeira & $\mathrm{X}$ & & & 8451 \\
\hline Davilla rugosa Poir. & árvore & $\mathrm{X}$ & & & 37195 \\
\hline \multicolumn{6}{|l|}{ ELAEOCARPACEAE } \\
\hline Sloanea guianensis (Aubl.) Benth. & árvore & & $\mathrm{X}$ & & 37550 \\
\hline Sloanea monosperma Vell. & árvore & $\mathrm{X}$ & $\mathrm{X}$ & & 27745 \\
\hline \multicolumn{6}{|l|}{ ERYTHROXYLACEAE } \\
\hline Erythroxylum citrifolium A.St.-Hil. & árvore & & $\mathrm{X}$ & & 34761 \\
\hline Erythroxylum pelleterianum A.St.-Hil. & árvore & & $\mathrm{X}$ & & 35037 \\
\hline \multicolumn{6}{|l|}{ EUPHORBIACEAE } \\
\hline Acalypha brasiliensis Müell.Arg. & arbusto & $\mathrm{X}$ & & & 27757 \\
\hline Actinostemon concolor (Spreng.) Müll.Arg. & árvore & & $\mathrm{X}$ & & 35327 \\
\hline Alchornea gladulosa Poepp. \& Endl. & árvore & $\mathrm{X}$ & $\mathrm{X}$ & & 34988 \\
\hline Alchornea triplinernia (Spreng.) Muell.Arg. & árvore & $\mathrm{X}$ & $\mathrm{X}$ & & 27759 \\
\hline Aparisthmium cordatum (Juss.) Baill. & árvore & $\mathrm{X}$ & & & 32973 \\
\hline Croton floribundus Spreng. & árvore & $\mathrm{X}$ & & & 35138 \\
\hline Croton lundianus Müll.Arg. & arbusto & $\mathrm{X}$ & & & 36684 \\
\hline Croton salutaris Casar & árvore & $\mathrm{X}$ & & & 36667 \\
\hline Croton urucuranus Baill. & árvore & $\mathrm{X}$ & & & 37426 \\
\hline Dalechampia tryphilla Lam. & trepadeira & & $\mathrm{X}$ & & 37191 \\
\hline Euphorbia brasiliensis Lam. & arbusto & $\mathrm{X}$ & & & 36680 \\
\hline Euphorbia pulcherrima Willd. ex Klotzsch. & arbusto & & $\mathrm{X}$ & & 39348 \\
\hline Mabea fistulifera Mart. & árvore & $\mathrm{X}$ & & & 27761 \\
\hline Manihot sculenta Crantz & arbusto & $\mathrm{X}$ & & & 27739 \\
\hline Maprounea guianensis Aubl. & árvore & $\mathrm{X}$ & & & 35146 \\
\hline Pera glabrata (Schott) Poepp. ex Baill. & árvore & $\mathrm{X}$ & $\mathrm{X}$ & & 27757 \\
\hline Sebastiania brasiliensis Spreng. & árvore & & $\mathrm{X}$ & & 35327 \\
\hline \multicolumn{6}{|l|}{ FABACEAE } \\
\hline Acacia martiusiana (Steud.) Bukart. & trepadeira & & $\mathrm{X}$ & & 35046 \\
\hline Acacia plumosa Lowe & trepadeira & & $\mathrm{X}$ & & 33995 \\
\hline Anadenanthera peregrina (L.) Spreng. & árvore & $\mathrm{X}$ & $\mathrm{X}$ & & 34124 \\
\hline Bauhinia longifolia D.Dietr. & árvore & & $\mathrm{X}$ & & 35313 \\
\hline Bauhinia pulchella Benth. & arbusto & $\mathrm{X}$ & & & 39343 \\
\hline Bauhinia radiata Vell. & trepadeira & $\mathrm{X}$ & & & 32969 \\
\hline Canavalia picta Mart. ex Benth. & trepadeira & & $\mathrm{X}$ & & 37916 \\
\hline Centrosema $\mathrm{sp}$ & trepadeira & & $\mathrm{X}$ & & 36674 \\
\hline $\begin{array}{l}\text { Chamaecrista desvauxii (Hassl.) } \\
\text { H.S.Irwin \& Barneby }\end{array}$ & arbusto & $\mathrm{X}$ & & & 39344 \\
\hline Chamaecrista nictitans (L.) Moench. & erva & $\mathrm{X}$ & & & 40080 \\
\hline $\begin{array}{l}\text { Chamaecrista rotundifolia (Pers.) } \\
\text { Greene var. rotundifolia }\end{array}$ & erva & $\mathrm{X}$ & & & 40082 \\
\hline Cleobulia multiflora Mart. ex Benth. & trepadeira & $\mathrm{X}$ & $\mathrm{X}$ & & 36677 \\
\hline Crotalaria brevifolia DC. & erva & $\mathrm{X}$ & & & 35004 \\
\hline Dalbergia frutescens (Vell.) Britton & árvore & & $\mathrm{X}$ & & 37559 \\
\hline Desmodium adscendens (Sw.) DC. & erva & $\mathrm{X}$ & & & 35038 \\
\hline Desmodium purpureum Hook. \& Arn. & erva & $\mathrm{X}$ & $\mathrm{X}$ & & 36196 \\
\hline Inga flagelliformis (Vell.) Mart. & árvore & & $\mathrm{X}$ & & 35007 \\
\hline
\end{tabular}




\begin{tabular}{|c|c|c|c|c|c|}
\hline Famílias e espécies & Hábito & Borda & Interior & Inselberg & CES. \\
\hline Inga laurina $(\mathrm{Sw}$.$) Willd$ & árvore & & $\mathrm{X}$ & & 40079 \\
\hline Inga platyptera Benth. & árvore & & $\mathrm{X}$ & & 34999 \\
\hline Machaerium acutifolium Vogel & árvore & $\mathrm{X}$ & $\mathrm{X}$ & & 35324 \\
\hline Machaerium gracile Benth. & árvore & $\mathrm{X}$ & & & 39353 \\
\hline Machaerium hirtum (Vell.) Stellfeld & árvore & $\mathrm{X}$ & & & 39345 \\
\hline Machaerium nictitans (Vell.) Benth. & árvore & & $\mathrm{X}$ & & 33996 \\
\hline Mimosa bimucronata (DC.) Kuntze & árvore & $\mathrm{X}$ & & & 35038 \\
\hline Mimosa scabrella Benth. & árvore & $\mathrm{X}$ & & & 36150 \\
\hline Mimosa setosa var. paludosa (Benth.) Barneby & arbusto & $\mathrm{X}$ & & & 37196 \\
\hline Mimosa velloziana Mart. & arbusto & $\mathrm{X}$ & & & 36683 \\
\hline Phaseolus sp. & erva & $\mathrm{X}$ & & & 34605 \\
\hline Piptadenia adiantoides (Spreng.) J.F. Macbr. & árvore & & $\mathrm{X}$ & & 40081 \\
\hline Piptadenia gonoacantha (Mart.) J.F.Macbr. & árvore & $\mathrm{X}$ & & & 33697 \\
\hline Piptadenia paniculata Benth. & árvore & $\mathrm{X}$ & & & 37429 \\
\hline Platypodium elegans Vogel & árvore & $\mathrm{X}$ & $\mathrm{X}$ & & 36682 \\
\hline $\begin{array}{l}\text { Pseudopiptadenia contorta (DC.) } \\
\text { G.P.Lewis \& M.P.Lima }\end{array}$ & árvore & & $\mathrm{X}$ & & 37556 \\
\hline $\begin{array}{l}\text { Senna macranthera (DC. ex Collad.) } \\
\text { H.S.Irwin \& Barneby }\end{array}$ & árvore & $\mathrm{X}$ & $\mathrm{X}$ & & 35050 \\
\hline Sesbania emerus (Aubl.) Urb. & arbusto & $\mathrm{X}$ & & & 32982 \\
\hline Tachigali densiflora (Benth.) Oliveira-Filho & árvore & $\mathrm{X}$ & & & 37551 \\
\hline $\begin{array}{l}\text { Tachigali rugosa (Mart. ex Benth.) } \\
\text { Zarucchi \& Pipoly }\end{array}$ & árvore & $\mathrm{X}$ & & & 35149 \\
\hline GESNERIACEAE & & & & & \\
\hline Sinningia agreggata (Ker-Gawl.) Wiehler & erva & & & $\mathrm{X}$ & 27778 \\
\hline $\begin{array}{l}\text { HELICONIACEAE } \\
\text { Heliconia angusta Vell. }\end{array}$ & erva & & $\mathrm{X}$ & & 32498 \\
\hline HUMIRIACEAE & & & & & \\
\hline Humiriastrum glaziovii (Urb.) Cuatrec. & árvore & & $\mathrm{X}$ & & 32814 \\
\hline $\begin{array}{l}\text { HYPERICACEAE } \\
\text { Sarothra brasiliensis (Choisv) Y.Kimura }\end{array}$ & & & & & \\
\hline $\begin{array}{l}\text { Sarothra brasiliensis (Choisy) Y.Kimura } \\
\text { Vismia magnoliifolia Cham. \& Scholtoll. }\end{array}$ & arbusto & $\begin{array}{l}\mathrm{X} \\
\mathrm{X}\end{array}$ & & & $\begin{array}{l}35333 \\
34602\end{array}$ \\
\hline HYPOXIDACEAE & alvoic & & & & \\
\hline Hypoxis decumbens $\mathrm{L}$. & erva & & $\mathrm{X}$ & & 36545 \\
\hline IRIDACEAE & & & & & \\
\hline Gladiolus sp. & erva & $\mathrm{X}$ & & & 34172 \\
\hline LAMIIACEAE & & & & & \\
\hline Aegiphila sellowiana Cham. & árvore & $\mathrm{X}$ & & & 35316 \\
\hline Hyptidendron asperrimum (Epling) Harley & árvore & & $\mathrm{X}$ & & 34986 \\
\hline Hyptis suaveolens (L.) Poit. & arbusto & $\mathrm{X}$ & & & 40089 \\
\hline Hyptis sp. & arbusto & $\mathrm{X}$ & $\mathrm{X}$ & & 39144 \\
\hline Hyptis mutabilis (Rich.) Briq. & arbusto & $\mathrm{X}$ & & & 34026 \\
\hline Salvia splends Ker-Gawl. & arbusto & & $\mathrm{X}$ & & 34997 \\
\hline Vitex sellowiana Cham. & árvore & $\mathrm{X}$ & $\mathrm{X}$ & & 37626 \\
\hline $\begin{array}{l}\text { LACISTEMATACEAE } \\
\text { Lacistema pubescens } \text { Mart. }\end{array}$ & árvore & & $\mathrm{X}$ & & 34182 \\
\hline LAURACEAE & & & & & \\
\hline Aniba firmula (Nees \& Mart.) Mez & árvore & & $\mathrm{X}$ & & 16293 \\
\hline Endlicheria paniculata (Spreng.) J.F.Macbr. & árvore & & $\mathrm{X}$ & & 35326 \\
\hline
\end{tabular}




\begin{tabular}{|c|c|c|c|c|c|}
\hline Famílias e espécies & Hábito & Borda & Interior & Inselberg & CESJ \\
\hline Nectandra lanceolata Nees & árvore & $\mathrm{X}$ & $\mathrm{X}$ & & 35322 \\
\hline Nectandra oppositifolia Nees & árvore & & $\mathrm{X}$ & & 27829 \\
\hline Ocotea cernиа $(\mathrm{Nees}) \mathrm{Mez}$ & árvore & & $\mathrm{X}$ & & 32666 \\
\hline Ocotea corymbosa (Meisn.) Mez & árvore & & $\mathrm{X}$ & & 34182 \\
\hline Ocotea dispersa $($ Nees $) \mathrm{Mez}$ & árvore & & $\mathrm{X}$ & & 40117 \\
\hline Ocotea villosa Kosterm. & árvore & & $\mathrm{X}$ & & 39135 \\
\hline \multicolumn{6}{|l|}{ LECYTHIIDACEAE } \\
\hline Lecythis pisonis Cambess. & árvore & & $\mathrm{X}$ & & 33992 \\
\hline \multicolumn{6}{|l|}{ LORANTHACEAE } \\
\hline Struthanthus concinnus Mart. & trepadeira & $\mathrm{X}$ & $\mathrm{X}$ & & 37186 \\
\hline Struthanthus marginatus (Desr.) Blume & trepadeira & $\mathrm{X}$ & & & 35033 \\
\hline \multicolumn{6}{|l|}{ LYTHRACEAE } \\
\hline Cuphea carthagenensis (Jacq.) J.F.Macbr. & erva & & $\mathrm{X}$ & & 39962 \\
\hline Cuphea ingrata Cham. \& Schltdl. & erva & & $\mathrm{X}$ & & 35141 \\
\hline Lafoensia pacari A.St.-Hil. & árvore & & $\mathrm{X}$ & & 40921 \\
\hline \multicolumn{6}{|l|}{ MALPIGHIACEAE } \\
\hline Banisteriopsis muricata (Cav.) Cuatrec. & trepadeira & $\mathrm{X}$ & & & 37192 \\
\hline Heteropterys fluminensis (Griseb) W.R.Anderson & trepadeira & & $\mathrm{X}$ & & 40078 \\
\hline Heteropterys pauciflora A.Juss. & trepadeira & $\mathrm{X}$ & & & 36671 \\
\hline Heteropterys sericea (Cav.) A.Juss. & trepadeira & $\mathrm{X}$ & & & 40090 \\
\hline Stigmaphyllon puberulum Griseb. & trepadeira & $\mathrm{X}$ & & & 39142 \\
\hline Stigmaphyllon sp. & trepadeira & $\mathrm{X}$ & & & 35143 \\
\hline Tetrapteris lucida A.Juss. & trepadeira & $X$ & & & 34994 \\
\hline \multicolumn{6}{|l|}{ MALVACEAE } \\
\hline Ceiba speciosa (A.St.-Hil.) Ravenna & árvore & $\mathrm{X}$ & $\mathrm{X}$ & & 38230 \\
\hline Eriotheca candolleana (K.Schum.) A .Robyns & árvore & $\mathrm{X}$ & $\mathrm{X}$ & & 27774 \\
\hline Luehea candicans Mart. \& Zucc. & árvore & & $\mathrm{X}$ & & 32507 \\
\hline Luehea grandiflora Mart. \& Zucc. & árvore & $\mathrm{X}$ & & & 33987 \\
\hline Ochroma pyramidale (Cav. ex Lam.) Urb. & árvore & $\mathrm{X}$ & & & 39342 \\
\hline Pavonia communis A.St.-Hil. & erva & $\mathrm{X}$ & & & 35317 \\
\hline Pseudobombax endecaphyllum (Vell.) A.Robyns & árvore & $\mathrm{X}$ & $\mathrm{X}$ & & 37921 \\
\hline Sida carpinifolia $\mathrm{L}$. & erva & $\mathrm{X}$ & $\mathrm{X}$ & & 34760 \\
\hline Sterculia chicha A.St.-Hil. & árvore & & $\mathrm{X}$ & & 39347 \\
\hline \multicolumn{6}{|l|}{ MELASTOMATACEAE } \\
\hline Leandra aurea (Cham.) Cogn. & arbusto & $\mathrm{X}$ & & $\mathrm{X}$ & 32664 \\
\hline Leandra purpurascens (DC.) Cogn. & arbusto & $\mathrm{X}$ & & & 35148 \\
\hline Leandra sericea (Mart.) DC. & arbusto & & $\mathrm{X}$ & & 33108 \\
\hline Leandra xanthostachya Cogn. & arbusto & & $\mathrm{X}$ & & 35330 \\
\hline Leandra sp.1 & arbusto & $\mathrm{X}$ & & & 34170 \\
\hline Leandra sp.2 & arbusto & $X$ & & & 34758 \\
\hline Miconia budlejoides Triana & árvore & & $\mathrm{X}$ & & 33699 \\
\hline Miconia cinnamomifolia (DC.) Naudin & árvore & & $\mathrm{X}$ & & 35049 \\
\hline Miconia latecrenata Triana & árvore & $\mathrm{X}$ & & & 35051 \\
\hline Miconia petropolitana Cogn. & árvore & $\mathrm{X}$ & & & 34014 \\
\hline Miconia prasina $(\mathrm{Sw}.) \mathrm{DC}$. & árvore & & $\mathrm{X}$ & & 34012 \\
\hline Miconia rimalis Naudin & árvore & & $\mathrm{X}$ & & 37193 \\
\hline Miconia robustissima Cogn. & árvore & $\mathrm{X}$ & $\mathrm{X}$ & & 36681 \\
\hline Miconia trianaei Cogn. & árvore & $\mathrm{X}$ & $\mathrm{X}$ & & 34600 \\
\hline Miconia urophylla DC. & árvore & $\mathrm{X}$ & & & 37686 \\
\hline Ossaea sp. & trepadeira & & $\mathrm{X}$ & & 32663 \\
\hline
\end{tabular}




\begin{tabular}{|c|c|c|c|c|c|}
\hline Famílias e espécies & Hábito & Borda & Interior & Inselberg & CESJ \\
\hline Siphanthera sp. & erva & & & $\mathrm{X}$ & 38413 \\
\hline Tibouchina arborea (Gard.) Cogn. & árvore & $\mathrm{X}$ & $\mathrm{X}$ & & 39136 \\
\hline Tibouchina estrellensis (Raddi) Cogn. & árvore & $\mathrm{X}$ & $\mathrm{X}$ & & 32670 \\
\hline Tibouchina sebastianopolitana (Raddi) Cogn. & erva & & $X$ & & 37553 \\
\hline \multicolumn{6}{|l|}{ MELIACEAE } \\
\hline Cabralea canjerana (Vell.) Mart. & árvore & $\mathrm{X}$ & $\mathrm{X}$ & & 41396 \\
\hline Cedrella fissilis Vell. & árvore & & $\mathrm{X}$ & & 32741 \\
\hline Guarea macrophylla Vahl & árvore & & $\mathrm{X}$ & & 33215 \\
\hline \multicolumn{6}{|l|}{ MENISPERMACEAE } \\
\hline Abuta selloana Eichler & trepadeira & $\mathrm{X}$ & $\mathrm{X}$ & & 34173 \\
\hline Chondodendron platiphylla (A.St.-Hil.) Miers & trepadeira & & $\mathrm{X}$ & & 35052 \\
\hline Cissampelos glaberrima A.St.-Hil. & trepadeira & $\mathrm{X}$ & & & 35318 \\
\hline Cissampelos verticillata Rhodes & trepadeira & & $\mathrm{X}$ & & 34996 \\
\hline \multicolumn{6}{|l|}{ MONIMIACEAE } \\
\hline Mollinedia argyrogyna Perkins & árvore & & $\mathrm{X}$ & & 34129 \\
\hline Mollinedia triflora (Spreng.)Tul. & árvore & & $\mathrm{X}$ & & 33896 \\
\hline \multicolumn{6}{|l|}{ MORACEAE } \\
\hline Brosimum guianense (Aubl.) Huber & árvore & & $\mathrm{X}$ & & 40088 \\
\hline Dorstenia arifolia Lam. & erva & & $\mathrm{X}$ & & 35136 \\
\hline Ficus citrifolia Mill. & árvore & & $\mathrm{X}$ & & 27889 \\
\hline Ficus enormis (Mart. ex Miq.) Mart. & árvore & & $\mathrm{X}$ & & 27890 \\
\hline Sorocea guilleminiana Gaudich. & árvore & & $\mathrm{X}$ & & 27776 \\
\hline \multicolumn{6}{|l|}{ MYRSINACEAE } \\
\hline Myrsine coriacea (Swartz) Roem. \& Schult. & árvore & & $\mathrm{X}$ & & 38452 \\
\hline Myrsine umbellata Mart. & árvore & $\mathrm{X}$ & $\mathrm{X}$ & & 27893 \\
\hline Myrsine venosa A.DC. & árvore & & $X$ & & 37428 \\
\hline \multicolumn{6}{|l|}{ MYRTACEAE } \\
\hline Campomanesia xanthocarpa O.Berg & árvore & $\mathrm{X}$ & $\mathrm{X}$ & & 32105 \\
\hline Eugenia cerasiflora Miq. & árvore & $\mathrm{X}$ & & & 37428 \\
\hline Marlierea laevigata (DC.) Kiaersk. & árvore & & $\mathrm{X}$ & & 35006 \\
\hline Myrcia eriopus DC. & arbusto & & $\mathrm{X}$ & & 32501 \\
\hline Myrcia splendens (Sw.) DC. & árvore & $\mathrm{X}$ & $\mathrm{X}$ & & 34171 \\
\hline Myrcia tomentosa (Aubl.) DC. & árvore & $\mathrm{X}$ & $\mathrm{X}$ & & 35310 \\
\hline Myrciaria glazioviana (Kiaersk.) Barroso ex Sobral & arbusto & & $\mathrm{X}$ & & 35133 \\
\hline Psidium cupreum $\mathrm{O}$. Berg & árvore & $\mathrm{X}$ & & & 35133 \\
\hline \multicolumn{6}{|l|}{ NYCTAGINACEAE } \\
\hline Guapira opposita (Vell.) Reitz & árvore & & $X$ & & 34177 \\
\hline \multicolumn{6}{|l|}{ ORCHIDACEAE } \\
\hline Sacoila lanceolata (Aubl.) Garay & erva & $\mathrm{X}$ & & & 37199 \\
\hline Oeaceoclades maculata (Lindl.) Lindl. & erva & & $\mathrm{X}$ & & 34184 \\
\hline Habenaria petalodes Lindl. & erva & $\mathrm{X}$ & $\mathrm{X}$ & & 37184 \\
\hline Cyrtopodium secumdum Jacq. & epífita & & $\mathrm{X}$ & & 28561 \\
\hline Epidendrum cardiochlinum Lindl. & epífita & & $X$ & & 32478 \\
\hline \multicolumn{6}{|l|}{ OXALIDACEAE } \\
\hline Oxalis hedysarifolia Pohl ex Progel & erva & $\mathrm{X}$ & & & 35315 \\
\hline Oxalis martiana Zucc. & erva & $\mathrm{X}$ & $\mathrm{X}$ & & 37554 \\
\hline \multicolumn{6}{|l|}{ PASSIFLORACEAE } \\
\hline Passiflora amethystina Mikan & trepadeira & & $\mathrm{X}$ & & 36153 \\
\hline Passiflora haematostigma Mart. ex Mast. & trepadeira & $\mathrm{X}$ & & & 40084 \\
\hline
\end{tabular}




\begin{tabular}{|c|c|c|c|c|c|}
\hline Famílias e espécies & Hábito & Borda & Interior & Inselberg & CESJ \\
\hline Passiflora miersii Mart. & trepadeira & $\mathrm{X}$ & & & 39351 \\
\hline Passiflora organensis Gard. & trepadeira & & $\mathrm{X}$ & & 37188 \\
\hline Passiflora speciosa Gard. & trepadeira & $X$ & $X$ & & 32505 \\
\hline \multicolumn{6}{|l|}{ PHYTOLACACEAE } \\
\hline Phytolacca americana $\mathrm{L}$. & arbusto & & $\mathrm{X}$ & & 34178 \\
\hline Seguieria americana $\mathrm{L}$. & árvore & & $\mathrm{X}$ & & 35043 \\
\hline \multicolumn{6}{|l|}{ PICRAMINACEAE } \\
\hline Picramnia parvifolia Engl. & árvore & & $\mathrm{X}$ & & 27149 \\
\hline \multicolumn{6}{|l|}{ PIPERACEAE } \\
\hline Peperomia galioides Kunth & erva & & & $\mathrm{X}$ & 35034 \\
\hline Piper arboreum subsp. arboreum Aubl. & erva & $\mathrm{X}$ & & & 35150 \\
\hline Piper klotzschianum (Kunth) C.DC. & erva & $\mathrm{X}$ & & & 36165 \\
\hline Piper mollicomum Kunth & erva & $\mathrm{X}$ & & & 32978 \\
\hline Piper propinquum C.DC. & erva & & $\mathrm{X}$ & & 32925 \\
\hline Piper tectoniifolium Kunth & erva & & $\mathrm{X}$ & & 35155 \\
\hline Piper umbellatum $\mathrm{L}$. & erva & $\mathrm{X}$ & & & 34595 \\
\hline \multicolumn{6}{|l|}{ POACEAE } \\
\hline Ichnanthus sp. & erva & & $\mathrm{X}$ & & 33109 \\
\hline Lasiacis sorghoidea (Desv. exHam.) Hitchc. \& Chase & erva & $\mathrm{X}$ & $\mathrm{X}$ & & 40087 \\
\hline Merostachys fischeriana Rupr. ex Döll & erva & & $\mathrm{X}$ & & 37178 \\
\hline Olyra micrantha Kunth & erva & & $\mathrm{X}$ & & 32539 \\
\hline Oplismenus hirtellus L. & erva & $\mathrm{X}$ & $\mathrm{X}$ & & 34597 \\
\hline Parodiolira micrantha (Kunth) Davidse \& Zuloaga & erva & $\mathrm{X}$ & $\mathrm{X}$ & & 9041 \\
\hline Setaria poiretiana (Schult.) Kunth & erva & $\mathrm{X}$ & $\mathrm{X}$ & & 34509 \\
\hline \multicolumn{6}{|l|}{ POLYGALACEAE } \\
\hline Bredemeyera velutina A.W.Bennet & trepadeira & $\mathrm{X}$ & & & 35005 \\
\hline Diclidanthera elliptica Miers. & trepadeira & $\mathrm{X}$ & & & 35047 \\
\hline Diclidanthera laurifolia Mart. & trepadeira & & & $\mathrm{X}$ & 32745 \\
\hline Polygala laureola A.St.-Hil. \& Moq. & arbusto & $\mathrm{X}$ & & & 33107 \\
\hline Polygala paniculata $\mathrm{L}$. & arbusto & $\mathrm{X}$ & & & 36669 \\
\hline Polygala sp. & arbusto & $\mathrm{X}$ & & & 37187 \\
\hline Polygala urbani Chodat & arbusto & $\mathrm{X}$ & & & 35323 \\
\hline Securidaca lanceolata A.St.-Hil. & trepadeira & & $\mathrm{X}$ & & 39350 \\
\hline Securidaca sp. & trepadeira & $\mathrm{X}$ & & & 39349 \\
\hline \multicolumn{6}{|l|}{ PORTULACACEAE } \\
\hline Portulaca oleracea L. & erva & $\mathrm{X}$ & & & 40086 \\
\hline Talinum patens (Jacq.) Willd. & erva & $X$ & & $X$ & 36672 \\
\hline \multicolumn{6}{|l|}{ PROTEACEAE } \\
\hline Euplassa rufa (Loes.) Sleumer & árvore & & $\mathrm{X}$ & & 36672 \\
\hline \multicolumn{6}{|l|}{ RHAMNACEAE } \\
\hline Colubrina glandulosa Perk. & árvore & & $\mathrm{X}$ & & 32975 \\
\hline Gouania ulmifolia Hook. \& Arn. & trepadeira & $\mathrm{X}$ & $\mathrm{X}$ & & 40076 \\
\hline \multicolumn{6}{|l|}{ ROSACEAE } \\
\hline Rubus urticifolius Poir. & arbusto & $\mathrm{X}$ & $\mathrm{X}$ & & 33104 \\
\hline Rubus rosifolius $\mathrm{Sm}$. var. rosifolius & arbusto & $\mathrm{X}$ & $\mathrm{X}$ & & 32314 \\
\hline \multicolumn{6}{|l|}{ RUBIACEAE } \\
\hline Amaioua guianensis Aubl. & árvore & & $\mathrm{X}$ & & 36670 \\
\hline Bathysa nicholsonii Schum. & árvore & & $\mathrm{X}$ & & 34504 \\
\hline Bathysa australis (A.St.-Hil.) Benth. \& Hook.f. & árvore & & $\mathrm{X}$ & & 34989 \\
\hline
\end{tabular}




\begin{tabular}{|c|c|c|c|c|c|}
\hline Famílias e espécies & Hábito & Borda & Interior & Inselberg & CESJ \\
\hline Borreria verticillata (L.) G.Mey. & erva & $\mathrm{X}$ & $\mathrm{X}$ & & 35040 \\
\hline Coccocypselum lanceolatum (Ruiz \& Pav.) Pers. & erva & & $\mathrm{X}$ & & 36164 \\
\hline Coffea arabica $\mathrm{L}$. & arbusto & & $\mathrm{X}$ & & 36670 \\
\hline Cordiera concolor (Cham.) Kuntze & árvore & $\mathrm{X}$ & & & 35053 \\
\hline Cordiera sessilis (Vell.) Kuntze & árvore & $\mathrm{X}$ & $\mathrm{X}$ & & 32525 \\
\hline Coutarea hexandra (Jacq.) K.Schum. & arbusto & & $\mathrm{X}$ & & 36167 \\
\hline Galium hypocarpium (L.) Engl. ex Griseb. & erva & $\mathrm{X}$ & & & 33701 \\
\hline Guettarda viburnoides Cham. \& Schltdl. & árvore & & $\mathrm{X}$ & & 37427 \\
\hline Manettia cordifolia Mart. & trepadeira & & $\mathrm{X}$ & & 35061 \\
\hline Manettia luteo-rubra (Vell.) Benth. & trepadeira & $\mathrm{X}$ & $\mathrm{X}$ & & 34601 \\
\hline Palicourea marcgravii A.St.-Hil. & arbusto & & $\mathrm{X}$ & & 35142 \\
\hline Psychotria bahiensis DC. & arbusto & & $\mathrm{X}$ & & 32524 \\
\hline Psychotria carthagenensis Jacq. & arbusto & $\mathrm{X}$ & $\mathrm{X}$ & & 33980 \\
\hline Psychotria cephalantha (Müll.Arg.) Standl. & arbusto & & $\mathrm{X}$ & & 32970 \\
\hline Psychotria malaneoides Müll.Arg. & arbusto & & $\mathrm{X}$ & & 37197 \\
\hline Psychotria nuda (Cham. \& Schltdl.) Wawra & arbusto & & $\mathrm{X}$ & & 32520 \\
\hline Psychotria cf. poeppigiana Müll.Arg. & arbusto & & $\mathrm{X}$ & & 32665 \\
\hline Psychotria pleiocephala Müll.Arg. & arbusto & & $\mathrm{X}$ & & 27923 \\
\hline Psychotria spathicalyx Müll.Arg. & arbusto & & $\mathrm{X}$ & & 27929 \\
\hline Psychotria stachyoides Benth. & arbusto & & $\mathrm{X}$ & & 39346 \\
\hline Psychotria vellosiana Benth. & arbusto & $\mathrm{X}$ & $\mathrm{X}$ & & 32524 \\
\hline Richardia brasiliensis Gomes & erva & $\mathrm{X}$ & & & 27956 \\
\hline \multicolumn{6}{|l|}{ RUTACEAE } \\
\hline Hortia arborea Engl. & árvore & $\mathrm{X}$ & $\mathrm{X}$ & & 36720 \\
\hline Zanthroxylum rhoifolium Lam. & árvore & $\mathrm{X}$ & $\mathrm{X}$ & & 39012 \\
\hline SALICACEAE & & & & & \\
\hline Casearia arborea (L.C.Rich.) Urb. & árvore & $\mathrm{X}$ & $\mathrm{X}$ & & 34748 \\
\hline \multicolumn{6}{|l|}{ SAPINDACEAE } \\
\hline Allophylus racemosus $\mathrm{Sw}$. & árvore & $\mathrm{X}$ & $\mathrm{X}$ & & 40085 \\
\hline Cardiospermum helicacabum L. & trepadeira & $\mathrm{X}$ & $\mathrm{X}$ & & 33298 \\
\hline Cardiospermum grandiflorum $\mathrm{Sw}$. & trepadeira & $\mathrm{X}$ & & & 32517 \\
\hline Cupania ludowigii Somner \& Ferruci & árvore & $\mathrm{X}$ & $\mathrm{X}$ & & 40092 \\
\hline Cupania oblongifolia Mart. & árvore & $\mathrm{X}$ & $\mathrm{X}$ & & 37920 \\
\hline Paullinia carpopoda Cambess. & trepadeira & & $\mathrm{X}$ & & 36664 \\
\hline Serjania sp.1 & trepadeira & $\mathrm{X}$ & $\mathrm{X}$ & & 27910 \\
\hline Serjania sp.2 & trepadeira & $\mathrm{X}$ & & & 37558 \\
\hline Serjania sp.3 & trepadeira & $\mathrm{X}$ & $\mathrm{X}$ & & 35321 \\
\hline \multicolumn{6}{|l|}{ SAPOTACEAE } \\
\hline Pouteria guianensis Aubl. & árvore & & $\mathrm{X}$ & & 27911 \\
\hline \multicolumn{6}{|l|}{ SIPARUNACEAE } \\
\hline Siparuna cujabana (Mart.) A.DC. & árvore & & $\mathrm{X}$ & & 32504 \\
\hline Siparuna guianensis Aubl. & árvore & $\mathrm{X}$ & $\mathrm{X}$ & & 34993 \\
\hline \multicolumn{6}{|l|}{ SMILACACEAE } \\
\hline Smilax campestris Griseb. & trepadeira & & $\mathrm{X}$ & & 35145 \\
\hline \multicolumn{6}{|l|}{ SOLANACEAE } \\
\hline Athenaea martiana Sendtn. & arbusto & & $\mathrm{X}$ & & 32977 \\
\hline $\begin{array}{l}\text { Aureliana fasciculata var. tomentella (Sendtn.) } \\
\text { Barbosa \& Huntz. }\end{array}$ & arbusto & & $\mathrm{X}$ & & 34992 \\
\hline Brugmansia arborea (L.) Lagerh. & arbusto & & $\mathrm{X}$ & & 35144 \\
\hline
\end{tabular}




\begin{tabular}{|c|c|c|c|c|c|}
\hline Famílias e espécies & Hábito & Borda & Interior & Inselberg & CESJ \\
\hline $\begin{array}{l}\text { Brunfelsia brasiliensis (Spreng.) } \\
\text { L.B.Sm. \& Downs }\end{array}$ & arbusto & $\mathrm{X}$ & & & 35134 \\
\hline Capsicum campylopodium Sendt. & arbusto & $\mathrm{X}$ & & & 32967 \\
\hline Cestrum amictum Schltdt. & arbusto & $\mathrm{X}$ & & & 36685 \\
\hline Cestrum pedicellatum Sendt. & arbusto & & $\mathrm{X}$ & & 33098 \\
\hline Cestrum viminale Sendt. & arbusto & & $\mathrm{X}$ & & 35312 \\
\hline Solanum alternatopinnatum Steud. & trepadeira & $\mathrm{X}$ & & & 35151 \\
\hline Solanum americanum Mill. & arbusto & $\mathrm{X}$ & & & 35044 \\
\hline Solanum caeruleum Vell. & arbusto & $\mathrm{X}$ & & & 36162 \\
\hline Solanum cernuит Vell. & arbusto & $\mathrm{X}$ & $\mathrm{X}$ & & 40093 \\
\hline Solanum concinnum Sendt. & arbusto & $\mathrm{X}$ & $\mathrm{X}$ & & 39140 \\
\hline Solanum hexandrum Vell. & arbusto & $\mathrm{X}$ & & & 33895 \\
\hline Solanum insidiosum Mart. & arbusto & $\mathrm{X}$ & $\mathrm{X}$ & & 32520 \\
\hline Solanum leucodendron Sendt. & árvore & & $\mathrm{X}$ & & 33986 \\
\hline Solanum swartzianum Roem. \& Schult. & árvore & $\mathrm{X}$ & $\mathrm{X}$ & & 36673 \\
\hline \multicolumn{6}{|l|}{ STYRACACEAE } \\
\hline Styrax latifolius Pohl & árvore & $\mathrm{X}$ & & & 32976 \\
\hline \multicolumn{6}{|l|}{ TRIGONIACEAE } \\
\hline Trigonia nivea Cambess. & trepadeira & $\mathrm{X}$ & $\mathrm{X}$ & & 36161 \\
\hline Trigonia paniculata Warm. & trepadeira & $\mathrm{X}$ & & & 39352 \\
\hline \multicolumn{6}{|l|}{ URTICACEAE } \\
\hline Cecropia glaziovii Snethl. & árvore & $\mathrm{X}$ & & & 35042 \\
\hline Cecropia hololeuca Miq. & árvore & $\mathrm{X}$ & $\mathrm{X}$ & & 33210 \\
\hline \multicolumn{6}{|l|}{ VERBENACEAE } \\
\hline Lantana brasiliensis Link & arbusto & $\mathrm{X}$ & $\mathrm{X}$ & & 32503 \\
\hline Lantana camara $\mathrm{L}$. & arbusto & $\mathrm{X}$ & $\mathrm{X}$ & & 33989 \\
\hline Stachytarphetta cajanensis Vahl & erva & $\mathrm{X}$ & $\mathrm{X}$ & & 35325 \\
\hline \multicolumn{6}{|l|}{ VIOLACEAE } \\
\hline Anchietea pyrifolia (Mart.) G.Don & trepadeira & & $\mathrm{X}$ & & 35325 \\
\hline Hybanthus brevicaulis (Mart.) Taub. & arbusto & & $\mathrm{X}$ & & 32924 \\
\hline \multicolumn{6}{|l|}{ VITACEAE } \\
\hline $\begin{array}{l}\text { Cissus verticillata ssp. verticillata (L.) } \\
\text { Nicholson \& Javis }\end{array}$ & trepadeira & & $\mathrm{X}$ & & 33905 \\
\hline \multicolumn{6}{|l|}{ VOCHYSIACEAE } \\
\hline Qualea selloi Warm. & árvore & & $\mathrm{X}$ & & 33905 \\
\hline Vochysia magnifica Warm. & árvore & & $\mathrm{X}$ & & 37917 \\
\hline
\end{tabular}

Tabela 2 - Índices de similaridade florística de Sorensen (metade superior direita) e Jaccard (metade inferior esquerda) calculados entre os três habitats definidos para o Morro do Imperador baseados nos habitats da vegetação.

\begin{tabular}{lccc}
\hline & Borda da Floresta & Interior da Floresta & Inselberg \\
\hline Borda da Floresta & - & 41,1 & 1,8 \\
Interior da Floresta & 25,8 & - & 0,0 \\
Inselberg & 0,9 & 0,0 & - \\
\hline
\end{tabular}




\section{Discussão}

As famílias com maior riqueza de espécies como Fabaceae, Asteraceae e Rubiaceae são também as únicas a possuir representantes em todos os hábitos e a ocorrer em todos os habitats, o que é amplamente relatado para a vegetação tropical (Whitmore 1990) e parcialmente justificado pela expressiva irradiação concomitante das mesmas desde o fim da última glaciação (Klein 1975).

Os gêneros mais ricos em espécies são, na maioria, arbustos do sub-bosque do Interior da Floresta, como Psychotria, Solanum e Piper. No entanto, este fato pode ter sido influenciado pela maior facilidade na coleta desses materiais devido ao porte das plantas e à disponibilidade de material fértil ao longo de boa parte do ano.

O gênero Miconia apresenta comportamento mais variado, sendo árvores e arbustos mais observados nas bordas que no interior. Segundo Goldenberg (2004), a distribuição espacial de Miconia é influenciada pelo nicho e deslocamento de muitas aves de borda de mata, como Traupídeos e Tiranídeos, dispersores potenciais da maioria das espécies desse gênero. Segundo estudo de frugivoria realizado em outro importante fragmento florestal do município (Manhães et al. 2003), Miconia urophylla é dispersa por mais de trinta espécies diferentes de aves de borda. Estes fatos provavelmente explicam porque as Melastomatáceas e Miconia, em particular, tendem a tornarem-se mais abundantes e ricas em espécies em florestas montanas do Domínio Atlântico quanto mais severo o histórico de perturbação das mesmas (Tabarelli \& Mantovani 1999a, 1999b). Além dos mecanismos de dispersão, provavelmente o grupo também inclui um grande número de espécies exigentes de luz e, portanto, pouco tolerantes à sombra do interior das florestas, mesmo quando esta é moderada pela semideciduidade.

Muitas famílias como Passifloraceae, Menispermaceae, Cucurbitaceae e Vitaceae são exclusivamente constituídas por espécies de trepadeiras ou possuem muitas espécies nesse hábito. O efeito de borda acentuado pelas estradas e trilhas que cortam os dois fragmentos florestais, provavelmente favorece e incrementa a expansão da biomassa vegetal de elementos destas famílias e, conseqüentemente, a competição pela luz com as árvores deve se intensificar, muitas vezes levando várias delas à morte, como já observado na borda de fragmentos de florestas semideciduais do estado de São Paulo (Viana et al. 1997). Isso foi observado em toda a borda da floresta do Morro do Imperador e é certamente mais vinculado ao incremento da biomassa de trepadeiras do que à riqueza de espécies, que é semelhante entre a Borda e o Interior.

As espécies encontradas nos afloramentos de granito-gnaisse, a superfície exposta do Inselberg, possuem alta especificidade, não só em relação ao ambiente como também ao hábito. A inerente dificuldade de acesso a estes materiais certamente contribuiu para subestimar a diversidade existente nesse habitat.

A menor riqueza e biomassa de epífitas nas Florestas Semideciduais em relação às Ombrófilas tem ampla relação com o gradiente de umidade (Gentry \& Dodson 1987; Benzing 1987; Benzing 1990). Contudo, no Morro do Imperador, esse número encontra-se bem abaixo do esperado em comparação com outras fitofisionomias semelhantes (L.C.Assis, dados não publicados).

Este fato é possivelmente justificado pelos inúmeros indícios de retirada seletiva de madeira e da exploração predatória de orquídeas e bromélias para o comércio ilegal. Não obstante, espécies exóticas como Salvia splendens e Euphorbia pulcherrima, encontradas no interior da mata, nos dão idéia da severidade das perturbações que vem sofrendo a mata do Morro do Imperador em decorrência tanto de sua localização quanto das políticas públicas de conservação, que são absolutamente inoperantes e ineficazes.

Os valores dos índices de similaridade de Sorensen são naturalmente maiores que os de Jaccard devido à própria formulação de cada índice. O primeiro atribui um valor dobrado às espécies em comum, enquanto que o segundo apenas atribui peso um a esse valor. Mesmo com tais diferenças, os dois índices apresentaram valores abaixo dos $50 \%$, o que corrobora com as relações 
estabelecidas entre as espécies e os habitas, culminando na clara distinção entre os mesmos em relação à composição florística. Explorando melhor a relação entre as espécies exclusivas e as compartilhadas por mais de um habitat é possível fortalecer ainda mais a distinção dos mesmos pela composição. Na relação entre a Borda e o Interior, onde o compartilhamento é mais evidente, as espécies mais freqüentes em cada habitat foram exclusivas dos mesmos em toda a floresta independente do fragmento. Como exemplos de espécies freqüentes e exclusivas de Borda em toda área de estudo estão: Ruellia macrantha Lindau, Davilla rugosa Poir., Vismia magnoliifolia, Richardia brasiliensis, Miconia urophylla e Miconia latecrenata Entretanto, como exclusivas do Interior têm-se: Psychotria cephalantha, Psychotria malaneoides, Piper propinquum, Piper tectoniifolium, Geonoma brevispata, Hatiora salicornioides e Rhipsalis lindbergiana.

É importante mencionar que em todas as campanhas de campo morfoespécies foram reconhecidos, embora estéreis, nos habitats de Interior e Borda preferencialmente em relação ao Inselberg. Evidenciando, desta forma, que o número de espécies exclusivas (ou mesmo preferenciais) da Borda e Interior é certamente ainda maior do que o encontrado, mostrando o quanto à assiduidade e a frequiência nos trabalhos de florística são fundamentais para minimizar as subestimativas. No entanto, é de conhecimento dos autores que muitas espécies falham em exibir fase reprodutiva por muitos anos seguidos, seja por motivos ligados ao histórico local das populações ou intrínsecos à biologia reprodutiva da espécie, como no caso dos bambus. A consequiência inescapável destes fatos é de que é praticamente impossível produzir um checklist rigorosamente completo da flora de áreas megadiversas de vegetação tropical. Além disso, a presença de duas espécies relatadas como primeiras ocorrências demonstram claramente como trabalhos dessa natureza são capazes de acrescentar informações valiosas e essenciais para o conhecimento da biodiversidade local. Tudo isso também agrega valor aos remanescentes de vegetação como repositórios de uma riqueza biológica ameaçada de rápido e irreversível desaparecimento.

A escassez de levantamentos florísticos, que contemplam todas as formas de vida, certamente restringiu as comparações dos resultados obtidos nesse estudo com outros levantamentos em formações semelhantes. Neste contexto, pela proximidade e semelhança fitofisionômica, apenas três levantamentos foram selecionados para as análises comparativas com o Morro do Imperador, dentre os quais estão os trabalhos realizados por Pifano (2007), Castro et al. (2004) e o trabalho de Lombardi \& Gonçalves (2000). Cabe ressaltar que as três áreas utilizadas nas comparações são Florestas Estacionais Semideciduais e que os dois primeiros trabalhos são localidades inseridas na Zona da Mata de Minas Gerais, enquanto que o terceiro e último situa-se no Vale do Rio Doce, leste desse estado.

A riqueza relativa das nove famílias mais representativas, nos quatro levantamentos florísticos comparados (Fig. 3), mostram um padrão semelhante de dominância das famílias Fabaceae, Rubiaceae, Asteraceae, Melastomataceae, Bignoniaceae e Orquidaceae. Em levantamentos florísticos realizados em formações ombrófilas do Domínio Atlântico (Garcia \& Pirani 2005; Lima \& Guedes-Bruni 1997) o mesmo padrão de riqueza foi observado, sendo um indicativo de como esses táxons são importantes no reconhecimento e caracterização deste Domínio. Não obstante, a distribuição fitogeográfica das árvores de Fabaceae, Rubiaceae e Melastomataceae indicam claramente como as florestas Atlânticas Semidecíduas são representadas por espécies da floresta Ombrófila capazes de tolerar períodos de seca mais prolongados (Oliveira-Filho \& Fontes 2000). É importante mencionar que a ausência de informações dessa natureza para as outras formas de vida limita tais discussões; contudo, a junção de dados fitogeográficos com as listagens florísticas revelam o quanto é difícil classificar essas fitofisionomias no Domininio Atlântico e, ainda, o quanto às formações interioranas do mesmo na Zona da Mata de Minas Gerais são pouco conhecidas e por isso mal classificadas. 


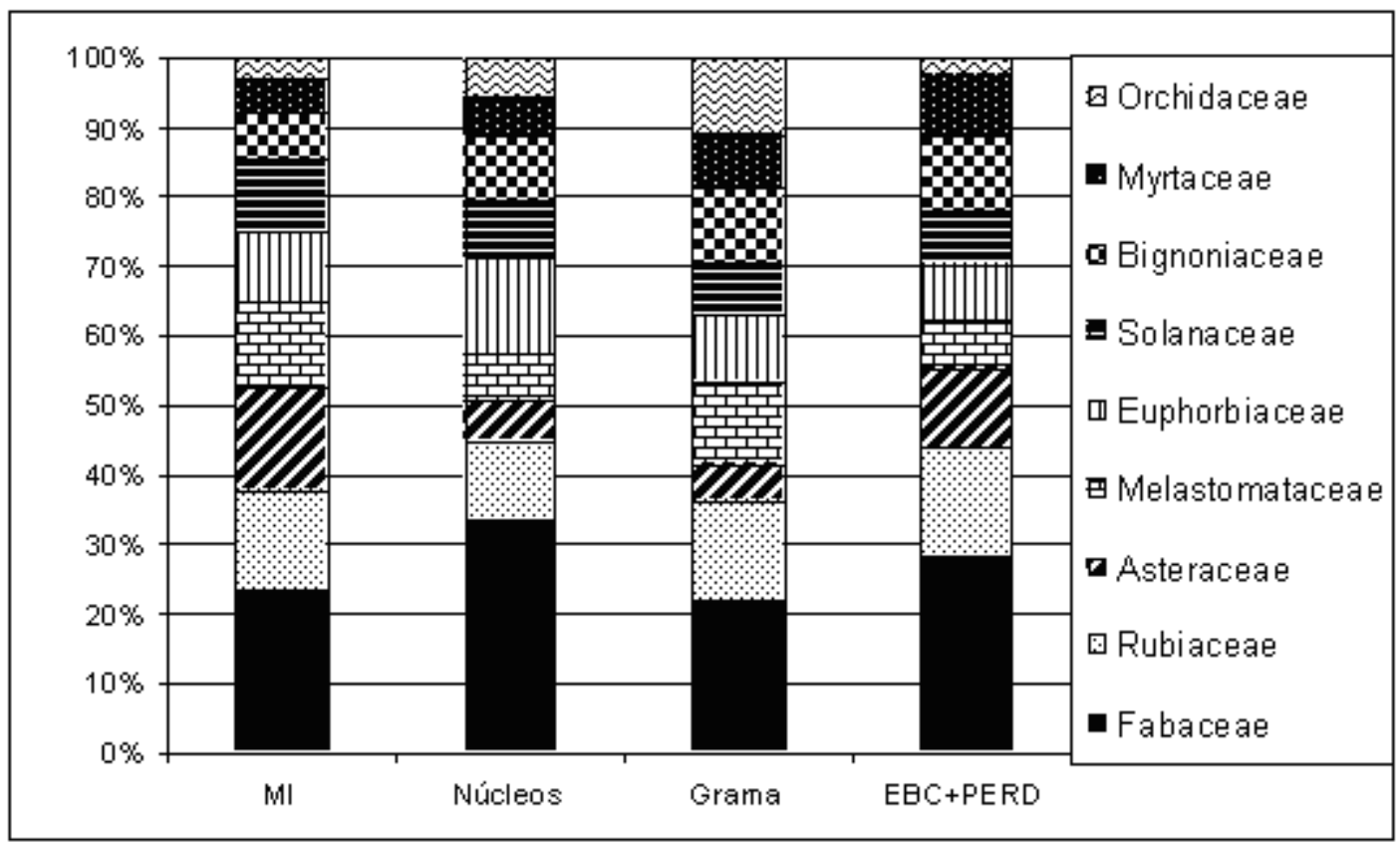

Figura 3 - Riqueza relativa das nove famílias mais representativas no Morro do Imperador (MI) comparadas com três outras áreas de Mata Atlântica: Núcleos = Sítio Arqueológico da Serra dos Núcleos, São João Nepomuceno, MG (Castro et al. 2004), Grama = Reserva Biológica da Represa do Grama, Descoberto, MG (Pifano 2007) e EBC + PERD, EBC = Estação Biológica de Caratinga e PERD = Parque Estadual do Rio Doce, Caratinga, MG (Lombardi \& Gonçalves 2000).

\section{Agradecimentos}

Aos pesquisadores Ricardo Oliveira Garcia e em especial, a Rafaela Campostrini Forzza pelo empenho, dedicação e esmero com que lidaram com este trabalho, sempre presentes em todas as fases de sua execução. Ao herbário Leopoldo Krieger por abrigar a coleção oriunda deste estudo e aos especialistas que, de boa vontade, sempre responderam aos envios auxiliando na construção sólida dos alicerces deste trabalho.

\section{REFERÊNCIAS BIBLIOGRÁFICAS}

Almeida, V. C. 1996. Composição florística e estrutura do estrato arbóreo de uma floresta situada na Zona da Mata Mineira, município de Lima Duarte, MG. Dissertação de Mestrado. Universidade Federal do Rio de Janeiro, Rio de Janeiro, 89p.

Almeida, D. S. \& Souza, A. L. 1997. Florística e estrutura de um fragmento de Floresta Atlântica, no município de Juiz de Fora, Minas Gerais. Revista Árvore 21(2): 221230.
APG [Angiosperm Phyllogeny Group] II. 2003. An update of the Angiosperm Phylogeny Group classification for the orders and familis of flowering plants: APG II. Botanical Journal of the Linnean Society 141: 399-436.

Armelin, R. S. \& Mantovani, W. 2001. Definições de clareira natural e suas implicações no estudo da dinâmica sucessional em florestas. Rodriguésia 52(81): 5-15.

Aubréville, A. 1959. As florestas do Brasil: estudo fitogeográfico florestal. Anuário Brasileiro de Economia Florestal 11: 210-232.

Benzing, D. H. 1987. Vascular epiphytism: taxonomic participation and adaptive diversity. Annals of the Missouri Botanical Garden 74: 183-204.

1990. Vascular epiphytes. Cambridge University Press, Cambridge.

Borges, V. V. 2006. Laboratório de Climatologia e Análise Ambiental. Departamento de Geociências/UFJF, 87p. 
Castro, P. S. 1980. Influência da cobertura florestal na qualidade da água em duas bacias hidrográficas na região de Viçosa, MG. Dissertação de Mestrado. Escola Superior de Agronomia Luiz de Queiroz, Piracicaba, 79p.

Castro, R. M.; Valente, A. S. M.; Garcia, R. O.; Pifano, D. S.; Antunes, K \& Salimena, F. R. G. 2004. Flora e Vegetação de um Sítio Arqueológico na Serra dos Núcleos, São João Nepomuceno-MG, Brasil. In: Oliveira, A. P. P. L. (ed.). Arqueologia e Patrimônio da Zona da Mata Mineira. Editar, Juiz de Fora. Pp.115-122.

Fernandes, A. 2003. Conexões florísticas do Brasil. $1^{a}$ ed. Banco do Nordeste, Fortaleza, 134p.

Fonseca, M. F. \& Vieira, V. B. 1995. Projeto: Contenção de encosta - sub-projeto: recomposição vegetal da vertente setentrional e oriental do Morro do Imperador. IPLAN, Prefeitura Municipal de Juiz de Fora, 113p.

Fontes, M. A. L. 1997. Análise da composição florística das florestas nebulares do Parque Estadual de Ibitipoca. Dissertação de Mestrado. Universidade Federal de Lavras, Lavras, 78p.

Garcia, R. J. F. \& Pirani, J. R. 2005. Análise florística, ecológica e fitogeográfica do Núcleo Curucutu, Parque Estadual da Serra do Mar (São Paulo, SP), com ênfase nos campos junto à crista da Serra do Mar. Hoenea 32(1): 1-48.

Gentry A. H. \& Dodson, C. H. 1987. Diversity and biogeography of neotropical vascular epiphytes. Annals of the Missouri Botanical Garden 74: 205-233.

Goldenberg, R. 2004. O gênero Miconia (Melastomataceae) no estado do Paraná. Acta Botânica Brasilica 18(4): 927-947.

Heringer, E. P. 1947. Contribuição para o conhecimento da flora da Zona da Mata de Minas Gerais (S.I): INPA, Boletim 2. 1987p.

Kent, M. \& Coker, P. 1992. Vegetation description and analysis. London: Belhaven Press, 327p.

Klein, R. M. 1975. Southern Brazilian phytogeographic features and the proble influence of upper quaternary climatic changes in floristic distribuition. Boletim Paranaense de Geociências 33: 67-88.

Lima, H. C. \& Guedes-Bruni, R. R. 1997. Diversidade de plantas vasculares na Reserva Ecológica de Macaé de Cima. In:Lima, H. C. \& Guedes-Bruni, R. R. (eds.). Serra de Macaé de Cima: Diversidade e Conservação em Mata Atlântica. Instituto de Pesquisas Jardim Botânico do Rio de Janeiro, Rio de Janeiro. Pp. 29-39.

Lombardi, J. A. \& Gonçalves, M. 2000. Composição florística de dois remanescentes de Mata Atlântica do sudeste de Minas Gerais, Brasil. Revista Brasileira de Botânica 23(3): 255-282.

Manhães, M. A.; Assis, L. C. S. \& Castro, R. M. 2003. Frugivoria e dispersão de sementes de Miconia urophylla DC. (Melastomataceae) por aves em um fragmento de mata atlântica secundária em Juiz de Fora (MG). Ararajuba: Revista Brasileira de Ornitologia 11(2): 173-180.

Meira-Neto, J. A., Sousa, A. L.; Silva, A. F. \& Paula, A. 1997. Estrutura de uma floresta estacional semidecidual submontana em área diretamente afetada pela Usina Hidrelétrica de Pilar, Ponte Nova, Zona da Mata de Minas Gerais. Revista Árvore 21(3): 337-344.

\& Martins, F.R. 2002. Composição florística do estrato herbáceo-arbustivo de uma Floresta Estacional Semidecidual em Viçosa-MG. Revista Árvore 24(4): 407-416.

\& Martins, F.R. 2002. Composição florística de uma Floresta Estacional Semidecidual Montana no município de Viçosa-MG. Revista Árvore 26(4): 437-446.

Nascimento, H. E. M. \& Laurance, W. F. 2006. Efeitos de área e de borda sobre a estrutura florestal em fragmentos de floresta de terrafirme após 13-17 anos de isolamento. Acta Amazônica 36(2): 183-192.

Oliveira-Filho, A. T. \& Fontes, M. A. L. 2000. Patterns of floristic differentiation among Atlantic forests in south-eastern Brazil, and the influence of climate. Biotropica 32(4b): 793-810. 
; Carvalho, D. A.; Fontes, M. A. L.; Van den Berg, E.; Curi, E. N. \& Carvalho, W. A. C. 2004. Variações estruturais do compartimento arbóreo de uma floresta semidecídua alto-montana na chapada das Perdizes, Carrancas, MG. Revista Brasileira de Botânica 27(2): 291-309.

\& Fluminhan-Filho, M. 1999. Ecologia da Vegetação do Parque Florestal Quedas do Rio Bonito. Cerne 5(2): 51-64.

Paniago, M. C. T. 1983. Evolucão histórica e tendências de mudanças sócio-culturais na comunidade de Viçosa-MG. Dissertação em Economia Rural. Universidade Federal de Viçosa, Viçosa, 407p.

Pifano, D. S. 2007. Composição da flora fanerogâmica da vegetação da Reserva Biológica da Represa do Grama, Descoberto, Minas Gerais. Dissertação de Mestrado. Universidade Federal de Lavras, Lavras, 111p.

Raunkiaer, C. 1934. The life forms of plants and statistical geography. Clarendon, Oxford, 632p.

Ribas, R. F.; Meira-Neto, J.A.; Silva, A. F. \& Souza, A. L. 2003. Composição florística de dois trechos em diferentes etapas serais de uma floresta estacional semidecidual em Viçosa, Minas Gerais. Revista Árvore 27(6): 821-830.

Scolforo, J. R. S. \& Carvalho, L. M. T. 2006. Mapeamento e inventário da flora nativa e dos reflorestamentos de Minas Gerais. Editora UFLA, Lavras. 236 p.

Silva, N. R. S.; Martins, S. V.; Meira Neto, J. A. \& Souza, A. L. 2004. Composição florística e estrutura de uma floresta estacional semidecidual montana em Viçosa, MG. Revista Árvore 28(3): 397-405.

Silva, S. F.; Oliveira, R. V.; Santos, N. R. L. \& Paula, A. 2004. Composição florística e grupos ecolológicos das espécies de um trecho de floresta semidecídua submontana da Fazenda São Geraldo, Viçosa-MG. Revista Árvore 27(3): 311-319.
SOS Mata Atlântica \& INPE 2002. Atlas dos remanescentes florestais da Mata Atlântica no período 1995-2000. Relatório final. http://www.sosmatatlantica.org.br/ atlas2002. (Acesso em: 19/09/2006).

SOS Mata Atlântica. 1998. Atlas da evolução dos remanescentes florestais e ecossistemas associados no domínio da Mata Atlântica no período 1990-1995. Fundação SOS Mata Atlântica, São Paulo, Brasil, 259p.

Souza, V. C. \& Lorenzi, H. 2005. Botânica Sistemática, Guia ilustrado para identificação das famílias de Angiospermas da flora brasileira, baseado em APG II. Nova Odessa. Instituto Plantarum, 640p.

Tabarelli, M. \& Mantovani, W. 1999a. Clareiras naturais e a riqueza de espécies pioneiras em uma floresta Atlântica montana. Revista Brasileira de Biologia 59(2): 251-261.

Tabarelli, M. \& Mantovani, W. 1999b. A regeneração de uma floresta tropical montana após corte e queima (São PauloBrasil). Revista Brasileira de Biologia 59(2): 239-250.

Veloso, H. P.\& Goes Filho, L. 1982. Fitogeografia brasileira, classificação fisionômica ecológica da vegetação neotropical. Projeto RADAMBRASIL, Série Vegetação. Salvador, Boletim Técnico 1, 80p.

Rangel Filho, A. L. R. \& Lima, J. C. A. 1991. Classificação da vegetação brasileira adaptada a um sistema universal. IBGE, Rio de Janeiro, 89p.

Viana, V. M.; Tabanez, A. A. J. \& Batista, J. L. 1997. Restoration and management of fragmented landscapes. In: Laurance, W. F \&. Bierregaard, R. O (eds.). Tropical forest remnants: ecology, management, and conservation of fragmented communities. University of Chicago Press, Chicago. Pp. 347-365.

Whitmore, T.C. 1990. An introdution to the tropical rain forests. Clarendon Press, Oxford, 187p. 